\title{
Fetal Gastrointestinal Tract
}

National Cancer Institute

\section{Source}

National Cancer Institute. Fetal Gastrointestinal Tract. NCI Thesaurus. Code C34166.

The development of the gastrointestinal tract after the eleventh week of gestation until the time of birth. 